Corrigendum

\title{
Corrigendum to "In Vitro Determination of Genotoxicity Induced by Brackets Alloys in Cultures of Human Gingival Fibroblasts"
}

\author{
Juan Pablo Loyola-Rodríguez ${ }^{(D)},{ }^{1}$ Ildelfonso Lastra-Corso, ${ }^{2}$ José Obed García-Cortés $\left(\mathbb{D},{ }^{2}\right.$ \\ Alejandra Loyola-Leyva, ${ }^{3}$ Rúben Abraham Domínguez-Pérez, ${ }^{4}$ David Avila-Arizmendi, ${ }^{5}$ \\ Guillermo Contreras-Palma, ${ }^{5}$ Cecilia González-Calixto, ${ }^{5}$ and Gabriela Cortés Sandoval ${ }^{6}$ \\ ${ }^{1}$ Universidad Popular Autónoma del Estado de Puebla (UPAEP), Puebla, Mexico \\ ${ }^{2}$ Universidad Autónoma de San Luis Potosí, San Luis Potosí, Mexico \\ ${ }^{3}$ CIACYT, Universidad Autónoma de San Luis Potosí, San Luis Potosí, Mexico \\ ${ }^{4}$ Universidad Autónoma de Quéretaro, Quéretaro, Mexico \\ ${ }^{5}$ Universidad Autónoma de Guerrero, Acapulco, Guerrero, Mexico \\ ${ }^{6}$ Doctorado Institucional en Ingeniería y Ciencia de Materiales, Universidad Autónoma de San Luis Potosí, \\ Av. Dr. Manuel Nava \# 6, Zona Universitaria, CP 78290, San Luis Potosi, SLP, Mexico
}

Correspondence should be addressed to Juan Pablo Loyola-Rodríguez; juanpablo.loyola8@gmail.com

Received 18 December 2020; Accepted 18 December 2020; Published 4 January 2021

Copyright (c) 2021 Juan Pablo Loyola-Rodríguez et al. This is an open access article distributed under the Creative Commons Attribution License, which permits unrestricted use, distribution, and reproduction in any medium, provided the original work is properly cited.

In the article titled "In Vitro Determination of Genotoxicity Induced by Brackets Alloys in Cultures of Human Gingival Fibroblasts" [1], Dr. Gabriela Cortés Sandoval was missing from the author list. Dr. Gabriela Cortés Sandoval contributed to the experimental design, data collection, and analysis, and the corrected author list is shown above.

\section{References}

[1] J. P. Loyola-Rodríguez, I. Lastra-Corso, J. O. García-Cortés et al., "In Vitro determination of genotoxicity induced by Brackets Alloys in Cultures of human gingival Fibroblasts," Journal of Toxicology, vol. 2020, Article ID 1467456, 6 pages, 2020. 